\title{
Wildfire-Atmosphere Interaction Index for Extreme Fire behaviour
}

\author{
Tomàs Artés ${ }^{1}$, Marc Castellnou ${ }^{2}$, Tracy Houston Durrant ${ }^{3}$, and Jesús San-Miguel ${ }^{1}$ \\ ${ }^{1}$ European Commission, Joint Research Centre (JRC), Ispra, Italy \\ ${ }^{2}$ Grup de Recolzament a Actuacions Forestals (GRAF), Generalitat de Catalunya, Carretera de l'Autònoma, sn. 08290 \\ Cerdanyola del Vallés, Spain \\ ${ }^{3}$ External consultant for the European Commission (Engineering Ingegneria Informatica S.p.A.) Engineering Ingegneria \\ Informatica S.p.A., Rome, Italy
}

Correspondence: Tomàs Artés (tomas.artes-vivancos@ec.europa.eu)

\begin{abstract}
During the last 20 years extreme wildfires have challenged firefighting capabilities. Often, the prediction of the extreme behaviour is essential for the safety of citizens and fire fighters. Currently, there are several fire danger indices routinely used by firefighting services, but they are not suited to forecast convective extreme wildfire behaviour at global scale. This article proposes a new fire danger index, extreme fire behaviour index (EFBI), based on the analysis of the vertical profiles of the atmosphere above wildfires as an alternative to the use of traditional fire danger indices. The EFBI evaluates the ease of interaction between wildfires and the atmosphere that could lead to convective, erratic and extreme wildfires. Results of this research in the analysis of some of the critical fires in the last years show that the EFBI can potentially be used to provide valuable information to identify convective fires and to enhance fire danger rating schemes worldwide.
\end{abstract}

\section{Introduction}

Fires have naturally occurred in nearly all world biomes, shaping ecosystems and landscapes but are intrinsically linked to human activities. As humans spread to colonize most regions of the world, they brought fire with them and used it as a tool in agriculture and cattle raising activities. Currently, over $90 \%$ of the fires that occur in the world are caused by humans, deliberately or accidentally (Balch et al., 2017; Short, 2017; San-Miguel-Ayanz et al., 2012). In most regions of the world the most prominent fire management policy is that of fire exclusion. Fires that are purposely or accidentally started affect human assets and are thus controlled and extinguished as fast as possible. Only fires in very high latitudes, where human dwellings do not exist, are left to burn naturally. In the context of this paper we use the term wildfires, referring to those fires that escape beyond human control and cause damage to human lives and properties. Nowadays, it is estimated that about 400 million ha of natural and agricultural lands are burnt annually, although it is recognized that this figure is likely a gross underestimate of the total area burnt in reality (Boschetti et al., 2019). These fires are responsible for about 17\% of global $\mathrm{CO}_{2}$ (Shi et al., 2015; Friedlingstein et al., 2019) emissions and result in great economic damage and the loss of human lives. Most wildfires occur in the vicinity of humans, as they are caused by humans, and thus they affect people and human assets in the area where they occur. In Europe, this inter-mingle of human dwellings and natural areas is referred to as the wildland urban interface(WUI) and corresponds to the area where most fires and burnt areas occur. 
The damage caused by fires in the WUI is thus much greater than that of fires occurring in remote areas. This last fact is due to the high adaptability of ecosystems(Pausas and Keeley, 2009, 2017), the damage accountability and mitigation done by civil protection policies.In recent years, the occurrence of extreme fire seasons has increased dramatically in many regions of the world, being associated in most cases with the effect that climate change is already posing on wildfire regimes and wildfire behaviour. Examples of these extreme wildfires were those occurring in Indonesia (2015), Chile (2016), California (USA, 2017, 2018,2020), Canada (2017), Portugal (2017), California (2018), Greece (2018), Australia (2019), Siberia (2019),

30 Argentina (2021), Brazil, Bolivia and Paraguay (2019). Common to these events was the explosive behaviour of the single fires, which resulted in the loss of many lives and huge economic damage. Several entities reported and analysed these wildfires that interact with the atmosphere(Delicado and Gomes; "Independente", 2017) increasing wind speed, causing sudden wind direction changes, local fire tornadoes(Lareau et al., 2018b; Pirsko et al., 1965) and vortexes(Khaykin et al., 2020).

Often, fire management agencies of the countries make use of past fire history to analyse the potential behaviour of future wildfires. Fires are characterized by their rate of spread and fire intensity and the weather and fuel conditions when they occurred. One of the most commonly used fire danger indices is the Canadian Fire Weather index (Van Wagner et al., 1974); this is currently used in many countries of the world (Van Wagner et al., 1987) and even at global scale (Vitolo et al., 2020). Other common fire danger indices are the Australian McArthur, the USA NFDRS or the Ketch-Byran index (McArthur, 1967; Deeming et al., 1977; Keetch and Byram, 1968). Most of these indices provide reasonable information on the potential of a wildfire to spread and cause damage. However, these indices do not evaluate the context of the atmosphere around the fire.

Wildfires are phenomena driven by fuel conditions, topography and weather. Fuel conditions are determined by rainfall, temperature and relative humidity among others factors. Some of these factors, such as wind and rainfall, are very dynamic in time while others are static and characterize the local fire behaviour, such as topography. The behaviour of extreme fires, which prevents the evacuation of the affected areas and the possibility of fire extinction, is often related to the interaction of the wildfire dynamics and the conditions of the atmosphere around it (also known as coupled effects).

A first approximation to take into account the atmospheric instability around wildfires was the Haines index (Haines and Service, 1988), which is usually computed between two different heights of the atmosphere above the fire. In cases of extreme wildfire events, the Haines index (Potter, 2018a) can identify dangerous fire spread conditions by using values of temperature and humidity at different elevations. Although the index was successfully used in large fire episodes in the USA (Potter, 2018b), it failed to explain or predict the behaviour of extreme fires that have happened recently (Pinto et al., 2020)).

The main objective of our work is to evaluate a new fire danger index (EFBI) that considers atmospheric conditions, which are not usually taken into account in most traditional fire danger rating indices, incorporating the effects of the interaction of the inner atmosphere created by the fire with the surrounding atmospheric conditions.

In some cases, the Haines index saturates (Potter, 2018a), remaining at its maximum value, as in the case of the fire in Pedrógão, in Portugal 2017 (San-Miguel-Ayanz et al., 2019). The aim of the EFBI is to summarize the factors that may imply a change in fire behaviour and to determine how easy is for the change in fire behaviour to happen. Several authors used factors for storm forecast such as the convective available potential energy (CAPE) and convective inhibition (CIN) to address fire behaviour (Moncrieff and Miller, 1976). Conditioned atmosphere stability was often a common factor of extreme wildfire 
events. Consequently, increasing the temperature at the surface could lead to atmospheric instability; causing local, dangerous and unexpected conditions.

Wildfire behaviour can be modeled by forest fire simulators, which provide a forecast of the fire intensity and spread. These simulators are based on semi-empirical (Rothermel, 1972) or physical (Mell et al., 2007) models and can be coupled with atmospheric simulation models (WRF-Fire, (Mandel et al., 2011), MESO-NH ForeFire (Baptiste Filippi et al., 2009)) or wind field production models Windninja, (Forthofer et al., 2009) to assess wildfire behaviour. However, as the numbers of coupled models grow, the simulation becomes computationally more expensive and it is difficult to gather the required input data without strong uncertainties. Therefore, fire danger ratings and the experience of meteorologists, civil protection officers and fire analysts play an important role in decision making. Moreover, it is not feasible to use coupled models for simulating all wildfires detected at global scale. The capacity to forecast the conditions under which these critical fires can develop is thus of paramount importance and essential for the prevention of damage to the population and human assets. We hereby present a fire danger index referred to as the Extreme Wildfire behaviour Index (EFBI), which looks into the interaction of the wildfire dynamics with the surrounding atmosphere and determines if the behaviour of an ignited fire can become critical, allowing it to develop into an extreme wildfire (Duane et al., 2021). It considers the atmospheric conditions incorporating the effects of the interaction of inner atmosphere created by the fire with the surrounding atmospheric conditions. The EFBI uses similar principles to those of the Haines Index but it summarizes the factors that may imply a change in fire behaviour and determines how easy is for the change in fire behaviour to happen. It takes advantage of the advances in weather forecast modeling and computational capabilities to enhance the predictability of extreme fire events.

We used a global wildfire database (GlobFire (Artés et al., 2019)) and ERA5 weather reanalysis data (Hersbach, 2016) to compute the EBFI over a set of wildfires. Our approach is suited to be computed at global scale using operational weather forecast models to determine when an ongoing large fire can develop extreme wildfire behaviour. First, Section 2 describes the proposed index, the workflow for wildfire event selection from the global wildfire database and the retrieval of the meteorological data and the description of three study cases. The results of the EFBI for the study cases are explained in Section 3. Finally, the conclusions are presented in Section 4.

\section{Data and methods}

The proposed EFBI relies on the premise that the atmosphere can cause a wildfire to become convective or the wildfire can disrupt the atmosphere creating a convective trend.

The extreme fire behaviour index(EFBI) is computed as follows:

$$
E F B I=\frac{((C A P E+C I N)-(C A P E P+C I N P))}{\Delta T}
$$


$C A P E=\int_{Z_{f}}^{Z n} g \frac{\left(T_{v, \text { parcel }}-T_{v, \text { env }}\right)}{T_{v, \text { env }}} d z$

90

$C I N=\int_{Z_{\text {bottom }}}^{Z t o p} g \frac{\left(T_{v, \text { parcel }}-T_{v, \text { env }}\right)}{T_{v, \text { env }}} d z$

$$
\left\{\Delta T \in \mathbb{R} \mid\left(\Delta T=T_{\text {bottomConv }}-T_{\text {bottom }}\right) \wedge C I N \leq 0 \wedge T_{\text {Conv }} \geq 0\right\}
$$

Where CAPE and CIN are defined by Eq. 2 and 3 and $\Delta T$ is the number of degrees required to achieve a null or negative convective inhibition energy (CIN) (Eq. 4). CAPE and CIN are recomputed with the increased temperature $\left(T_{\text {bottom }}+\Delta T\right)$ and called CAPEP and CINP, CINP value being zero or higher than zero (no inhibition). The proposed EFBI determines the amount of increase in temperature degrees at the surface required to cause a null CIN and quantifies the change in the convective trend (addition of CAPE and CIN), allowing the prediction of fast fire spread due to convection.

In cases in which the atmosphere is already unstable, CIN is equal to or less than 0 being $\Delta T=0$, the values assigned to the index are the full integration of CAPE+CIN.

The EFBI is expressed in $\mathrm{Jg}-1^{\circ} \mathrm{C}-1$, which is the amount of energy exchange per unit of mass and per degree of temperature. The value can be used as an estimation of potential wildfire-atmosphere interaction.

High values of EFBI point to a sudden change of energy per mass for a small temperature increase (low value $\Delta T$ and high value of total convective energy). Under these conditions, air can potentially move vertically creating local conditions which are not explicitly provided by meteorological forecasts. When the values are low, the magnitude of the change is small and/or a higher temperature is required at the surface to cause any change. This information is essential for firefighters, since local eddies and sudden weather changes can occur and lead to very fast ember spotting fire spread, which create dangerous and unpredictable conditions for the front line safety (Lareau et al., 2018a).

To test the EFBI, we propose two machine learning approaches, a decision tree and a multilayer perceptron. EFBI and FWI were used to evaluate the discriminatory potential between two classes; small (500ha during more than one day) and large fires (10000ha in one day). Fire events were extracted from GlobFire database. The thresholds were chosen to consider both average and extreme fire spread. Small size fires were selected in the same zones where the large fires were selected, but in a different year, always outside the area burnt by the large fires. Using the same zone for both sets of fires we limited the variability in fuel and topography, ensuring that the differences in fire behaviour were due to the meteorological conditions under which the fires evolved. Often small fires are caused by fire spotting or the result of agricultural practices. To avoid these types of fires, it was required that the fires had more than $90 \%$ of the burnt area in wild land vegetation. The final selection was a total of 445 cases, with 223 fires larger than 10000ha and 222 fires smaller than 500ha. Figure 1 shows the distribution and the year of each fire at global scale. 


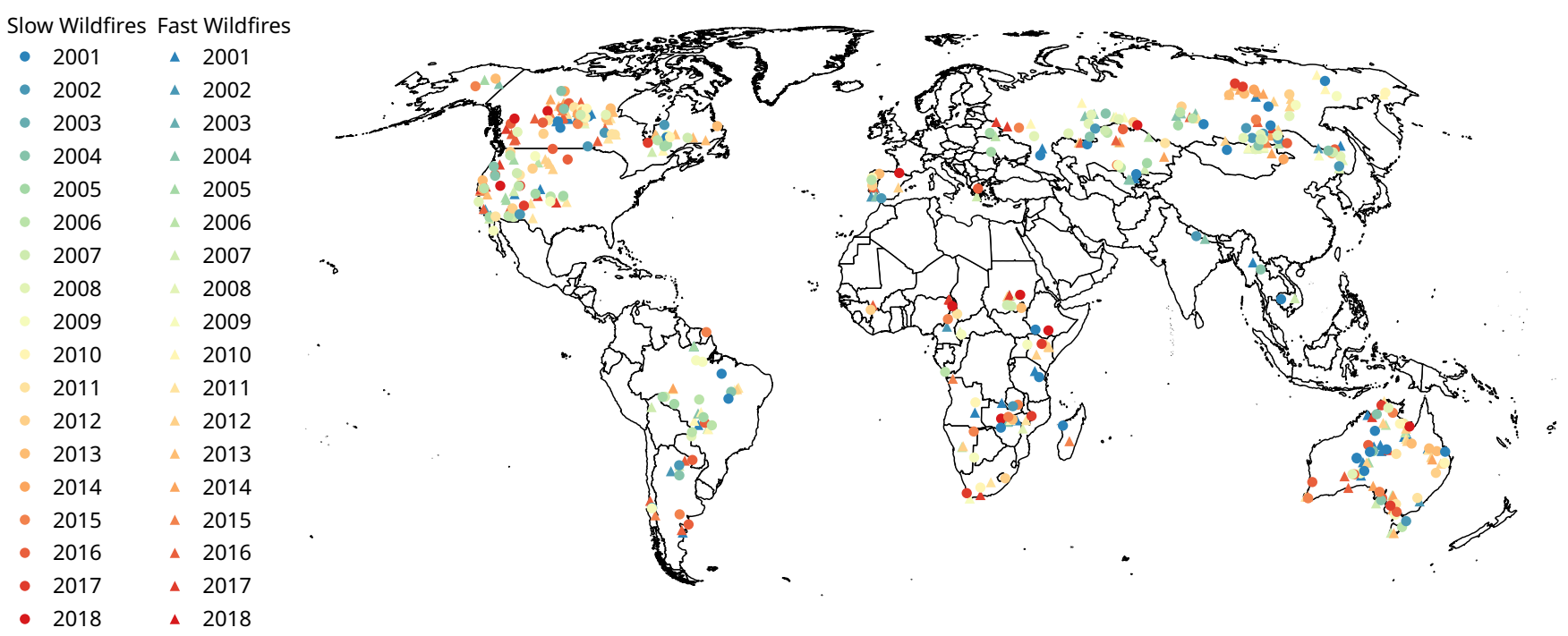

Figure 1. Location of the wildfires coloured by year. Fast fires and slow fires are depicted with triangles and circles respectively.

For each fire, the Canadian Fire Weather index (FWI) and all its components were retrieved from the ECMWF ERA5 dataset at 0.25 degrees resolution (Vitolo et al., 2020). In order to differentiate between agricultural fires or wildfires, the land cover from the Climate Change Initiative, CCI, (Defourny et al., 2012) was used, requiring that $90 \%$ of the burnt area was forest or shrubs, and thus avoiding fires in crops or agricultural areas. For each selected fire, temperature, relative humidity and wind profile were retrieved for all the heights above the wildfire event using the application user interface (API) of the Climate Data Store (CDS) for the ERA5 reanalysis dataset(Hersbach, 2016). Then, the EFBI and the vertical profiles for every event were computed, producing skew-t plots for every time step and generating plots with the time evolution of the index and the factors used for the computation of the EFBI. The aim of the skew-t plots is to visualize the ease with which the fire may become convective given an atmosphere context.

All the parameters obtained from FWI and EFBI were used to compute the mutual information(MI) of the wildfires that spread more than 10000ha in one day(large) or less than 500ha in more than one day(small). The MI has been chosen to quantify the individual importance of the variables gathered for each fire (such as the FWI components and EFBI) in relation to the speed of the spread of the fire, which is categorized into either small or large fire events. The FWI was computed for an entire day, and EFBI was computed with one hour time steps. Therefore, the values of the EFBI were aggregated using the minimum, the maximum and the average value for the time window. In addition, the date associated with the burnt area was based on GlobFire which uses the burnt area product of MODIS MCD64A1(Giglio et al., 2015). Due to clouds or dense smoke plumes, it is possible that a fire might have not been detected until some days after its ignition. To account for this delay, the initial day of the time window for the FWI and EFBI was increased by two days. The maximum value of the FWI and its 
components during the time window were selected. When applying FWI at global scale its values are not comparable between different locations. Despite that fact, the percentiles of FWI can provide information about the fire danger for a given area. Therefore, the values of the FWI were used in percentile values, computed for the period 1979 to 2019 of the same week of the year.

The MI for continuous values was computed using the method described in (Kraskov et al., 2004) and (Ross, 2014) using (Pedregosa et al., 2011). These methods use nearest neighbours with a random initialization; for that reason, 10 additional attributes were added to the analysis with random values to evaluate the noise of the MI. The MI computation was done 1000 times. The computations of MI were initialized with random values to evaluate the noise of the attributes for the MI computation.

In addition, the behaviour of the EFBI is shown analysing three different study cases. First, the fire in Pedrógão Grande, Portugal in 2017 using high spatial and temporal resolution fire perimeters. Following, EFBI is used with forecast data using daily fire perimeters of the wildfire that took place in Robore Bolivia in 2019. Lastly, the spatial distribution of EFBI for the set of extreme wildfires in the southeast coast in Australia at the end of 2019.

\section{Results}

EFBI results are evaluated combining the resulting values of the EFBI and FWI (Vitolo et al., 2020) to predict extreme fire behaviour observed in GlobFire using weather data from ERA5 (Hersbach, 2016). In this work, a machine learning approach is used to check the feasibility of using the EFBI to predict extreme convective wildfire behaviour at global scale. In addition, the EFBI values are shown for several study cases.

In Fig. 2, we illustrate how EFBI components behave for a given vertical profile at given time step. The blue area is the descending air trend (CIN), and the red area (from level of free convection (LFC) point to equilibrium level (EL)) is the ascending air trend (CAPE). When CIN values are low and CAPE values are high, wildfires can be convective at high altitudes. A temperature increase at the surface can reduce CIN values and increase CAPE values. Figure 2 shows a Skew-t plot with the parameters used to compute the EFBI. The figure shows the vertical profile of the atmosphere with the temperature as a red line and the temperature dew point in green at different altitudes(right vertical axis). These parameters are enough to compute the amount of work caused by the buoyancy force. By modifying temperature and dew point temperature the buoyancy changes, and consequently, the trend of the air to move. Figure 2 shows how a change of 14 degrees Celsius at the surface causes a considerable change in the vertical air motion, and a stable atmosphere becomes unstable, with a CAPEP close to $2443 \mathrm{Jkg}-1$ and a low value of CINP. Therefore, the amount of work due to the buoyancy change, passes from $34 \mathrm{Jkg}-1$ (CAPE) to 2443 Jkg-1(CAPEP) when CIN is not an inhibition (passing from a negative value to a positive value). This leads to a total change of $233.531 \mathrm{Jkg}-1^{\circ} \mathrm{C}-1$ per each degree increase at the surface. A wildfire in this condition has a high likelihood of convective behaviour. The CAPEP is around $2443 \mathrm{Jkg}-1$ when thunderstorms often exceed CAPE values of $1000 \mathrm{Jkg}-1$ and $5000 \mathrm{Jkg}-1$ in extreme cases (Lombardo and Colle, 2011). 
It is worth mentioning that CIN values at lower heights are also related with the temperature dew point at the surface (green line at $1000 \mathrm{hPa}$ ). With a constant temperature at the surface and an increase of dew point temperature, the CIN is reduced and therefore the EFBI increases. This may happen with a sudden increase of humidity at the surface, without any increase of temperature (already taken into account in the computation of the EFBI).

The timeline of the EFBI for the wildfire in Sala (2014, Sweden) is shown in Fig. 3. The time period when the fire had an extreme behaviour, as documented by firefighters on the ground, is delimited with vertical dashed lines. In this period, the modified convective available energy reaches values above $2500 \mathrm{~J} * \mathrm{~kg}-1$ and the index values are near $800 \mathrm{Jkg}-1^{\circ} \mathrm{C}-1$.

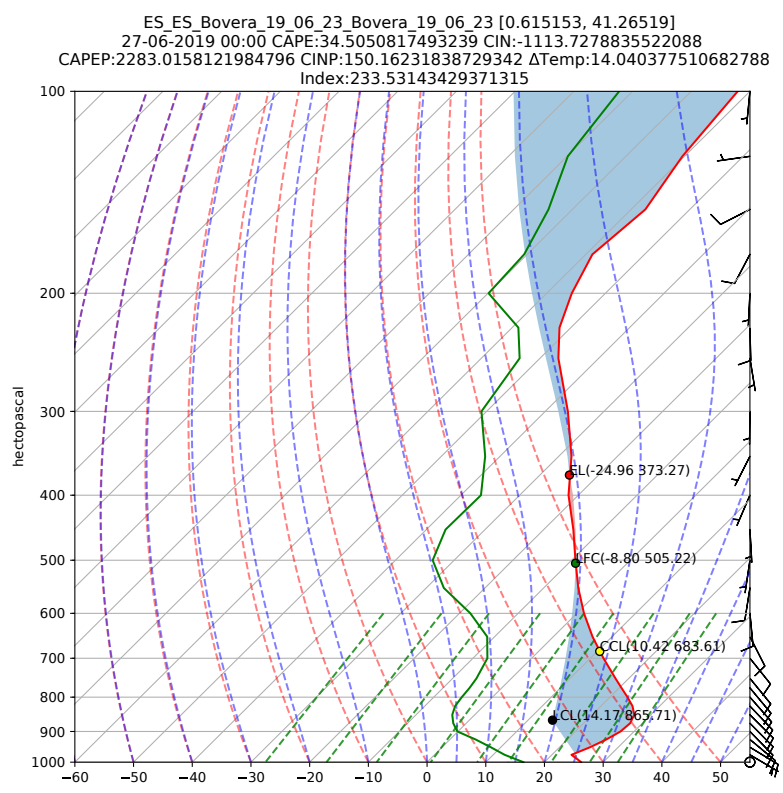

Figure 2. Sample of one Skew-t plot for a given time step for the wildfire that took place in Torre del Español (Spain) that burnt $6625 \mathrm{ha}$ from 26th to 27 th June of 2019.

The EFBI is computed for each time step, as explained in the previous illustrative example, for all the cases extracted from GlobFire database using the method described in section 2. Regarding the information of the different features used to discriminate small from large fires, Fig.4 shows the values of the MI mean and standard deviations of each attribute for the 1000 iterations. Using only the minimum, maximum or average of the EFBI was shown to provide more information to separate small from large fires than the percentile of the drought code (DC) of the FWI. Figure 4 is not a discriminatory power, but the amount of information that the factors individually contribute to the classification between the two classes. EFBI on its own cannot easily discriminate between the classes without using factors included in the computation of the FWI such as fine fuel moisture content (FFMC), duff moisture code(DMC) or drought code(DC). The discriminatory potential between the two classes using the EFBI is very low without using the FWI. 


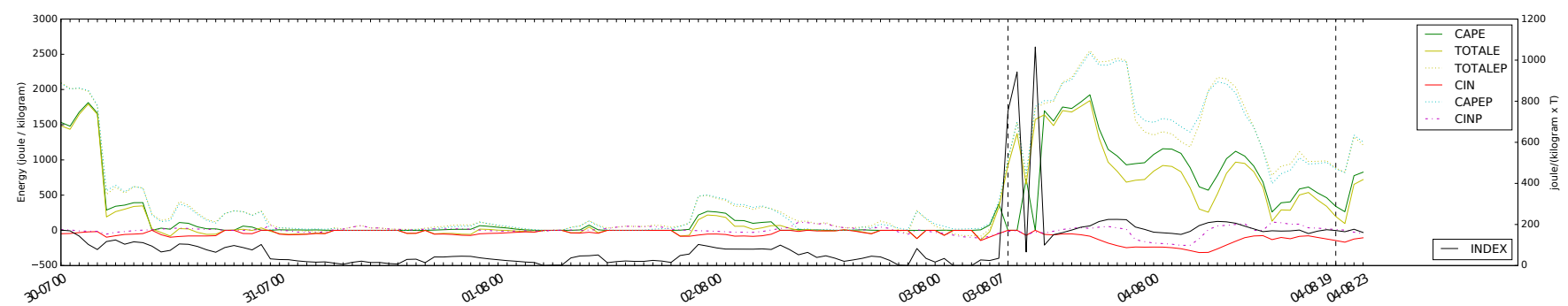

Figure 3. Sample of time line of the EFBI (right vertical axis) and the factors used (left vertical axis) for the wildfire in Sala (2014, Sweden) that burnt close to 10000 ha from $3 \mathrm{~h}$ to 4 th August of 2014 (time period marked with vertical dashed lines). Horizontal axis is the time line using hourly steps in format $\mathrm{dd} / \mathrm{mm} \mathrm{hh}$.

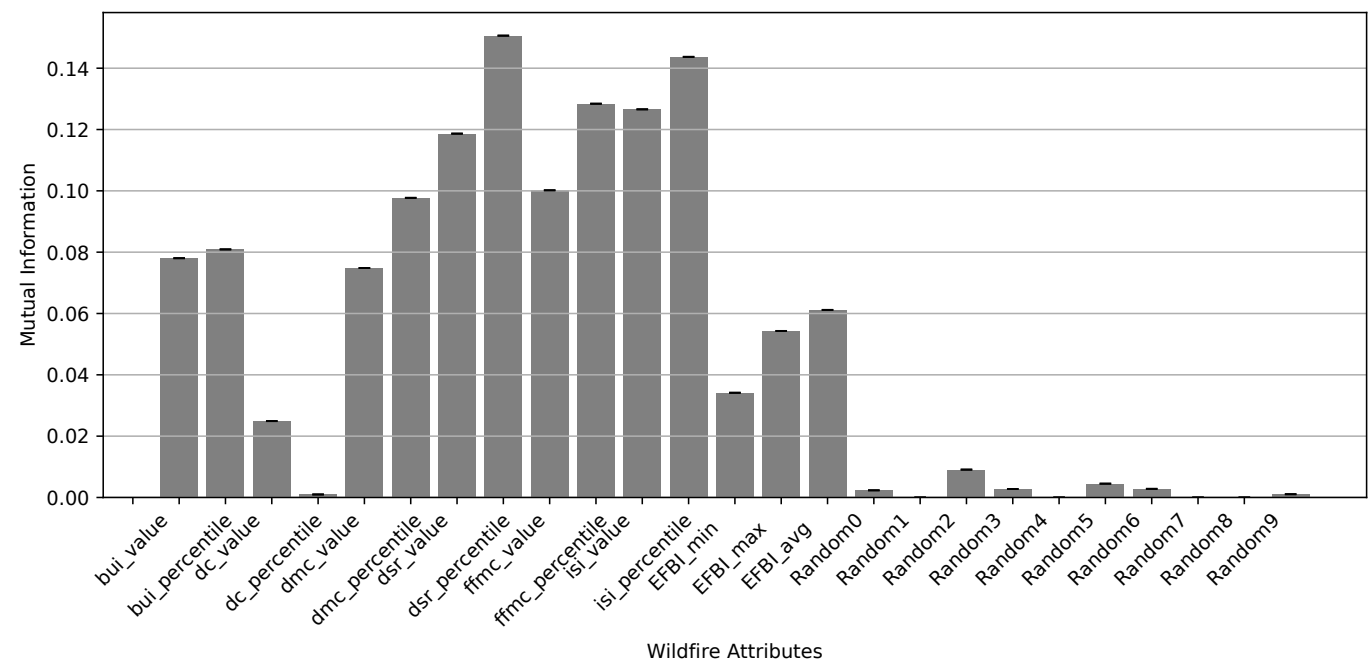

Figure 4. Mutual information of the different attributes gathered for each fire regarding their tag as fast or slow fires.

For instance, the EFBI can have high values after a rainfall event. It is thus important to stress that the EFBI becomes relevant when combined with the FWI components. A decision tree based on information gain as criteria was used to show the relevance of the EFBI in discriminating small fires from large fires. Figure 5 shows the decision tree, which is based on entropy reduction with a maximum depth of 4 levels (for visualizing purposes). The root uses the daily severity rating (DSR), which is a transformation of the FWI. At the second level, the maximum value of the EFBI is used, before any of the FWI components such as the percentiles of the initial spread index (ISI), the drought code (DC), the built up index (BUI) and the fine fuel moisture content (FFMC). Therefore, EFBI helps to reduce the entropy when discriminating between the two classes at global scale, being more relevant than the ISI or DC percentile.

A machine learning approach was applied using a decision tree and a multilayer perceptron. Removing the maximum depth restriction to the decision tree and performing a cross-validation of 1000 splits with $5 \%$ of cases, as a test, the average accuracy 


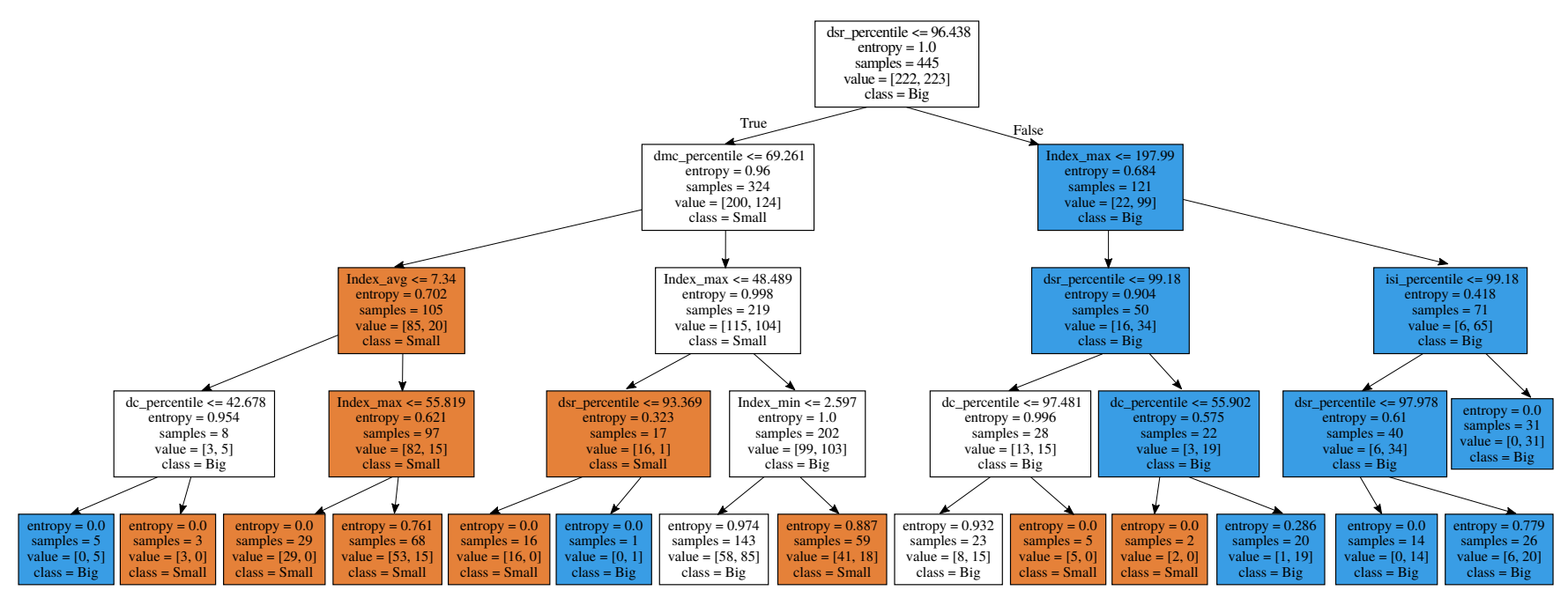

Figure 5. Decision tree based on entropy reduction build with the 445 wildfire events ( 222 small and 223 large wildfires).

was $65,13 \%$ with a standard error of $7.29 \%$. The accuracy was computed using Scikit Learn considering the accuracy of the percentage of each sample that each label is correctly predicted.

Applying a multilayer perceptron with 30 neurons and 130 hidden layers using a Broyden-Fletcher-Goldfarb-Shannowith LBFGS, (Byrd et al., 1995) optimizer for training, and the same parameters for a cross-validation, an accuracy of 65,46\% was reached. If the parameters related with the FWI were exclusively used, the accuracy decreased to 58\%.

As previously mentioned in Section 2, the dataset used to test the EFBI was obtained using a fully automated process. The information regarding the fire behaviour was obtained from GlobFire using SQL queries. The query guarantees that there are no fires happening in a 2 degree radius around a detected fire during a time period of 30 days. During the cross-validation process, the wildfires that were more frequently misclassified can be identified. When looking at the first 50 wildfires that are often misclassified, the proportion of the cases is very balanced between true small and large fire cases. Assuming that such cases are a source of noise and can be deleted from the dataset, the accuracy rises to $72 \%$. It should be noted that some cases could be false positives or false negatives. False positives could happen when a fire was burning in a cloudy area for several days. Once the area is free of clouds, the burnt area is detected for that day but it was burning for days before that. False negatives may have happened with re-ignitions of large fires. Besides, large fires are not always convective or related to an unstable atmosphere. The current automated process to discriminate potential large fires using the GlobFire database can be implemented in near-real time, using weather forecast data, allowing the potential identification of dangerous convective fires in advance, and thus increasing wildfire danger rating. This, in turn, would increase preparedness for firefighting procedures and enhance the safety of crews on the ground. Additionally, the overall procedure in the discrimination of potential large fires can be improved if the dataset is manually checked and the fire types are better defined. 


\subsection{Study Cases}

\subsubsection{Pedrógão Grande, Portugal 2017}

This wildfire had some of the most severe fire behaviour in Europe. The fire was ignited on 17th June and ran until 23th June. Figure 6 shows an explosive expansion from 17th June to 18th June, which is followed by a constant but severe fire expansion. For this analysis the fire perimeters made for a wildfire report done by a technical commission ("Independente", 2017) were used as reference for the fire spread.

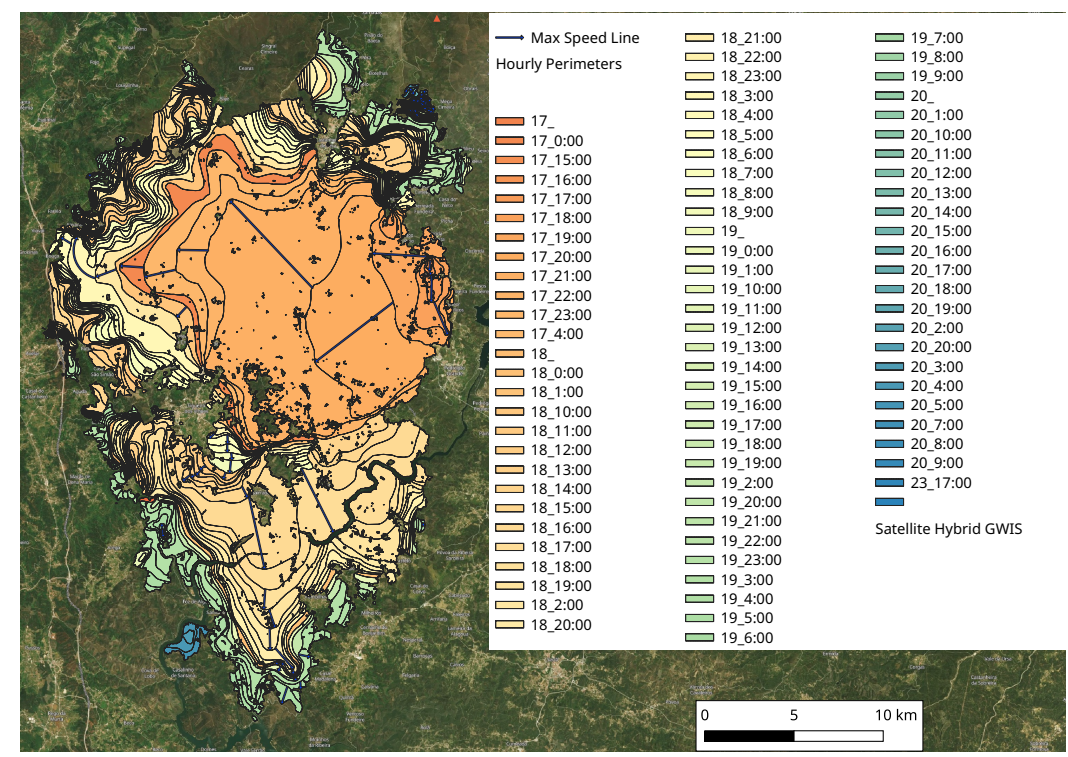

Figure 6. Time sequence of the wildfire which took place in Pedrógão Grande ("Independente", 2017), Portugal on 17th June of 2017. The maximum speed line between time steps is shown with a black arrow. Background image @MapTiler (https://maptiler.com/copyright).

From 17th to 18th June there was an increase of burnt area larger than 20000ha in one day.

Figure 7 shows the value of the EFBI and its components during the entire month for the fires computed from the ERA5 reanalysis; the two vertical dashed lines in the figure delimit the duration of the fire. The EFBI shows that there is a considerable potential for the interaction of the fire with the atmosphere. In addition, during the days of the fire there was a natural CAPE of nearly $5000 \mathrm{~J}^{*} \mathrm{~kg}-1$ inhibited by a small value of CIN. Increasing the temperature at the surface removing the inhibition, would produce a sudden convection. The index values are close to $250 \mathrm{~J} * \mathrm{~kg}-1$ per temperature degree increased and a total convective energy about $6000 \mathrm{~J} * \mathrm{~kg}-1$.

This case shows a natural tendency towards a convective behaviour that may be caused by the atmospheric instability itself, without the need for a considerable amount of heat and/or an increase in relative humidity at the surface.

For this case study, detailed fire perimeters for each time step were available, which makes it possible to analyse the relation between the maximum fire spread and the EFBI. Figure 8 shows a scatter plot where each point is a time step given an EFBI 


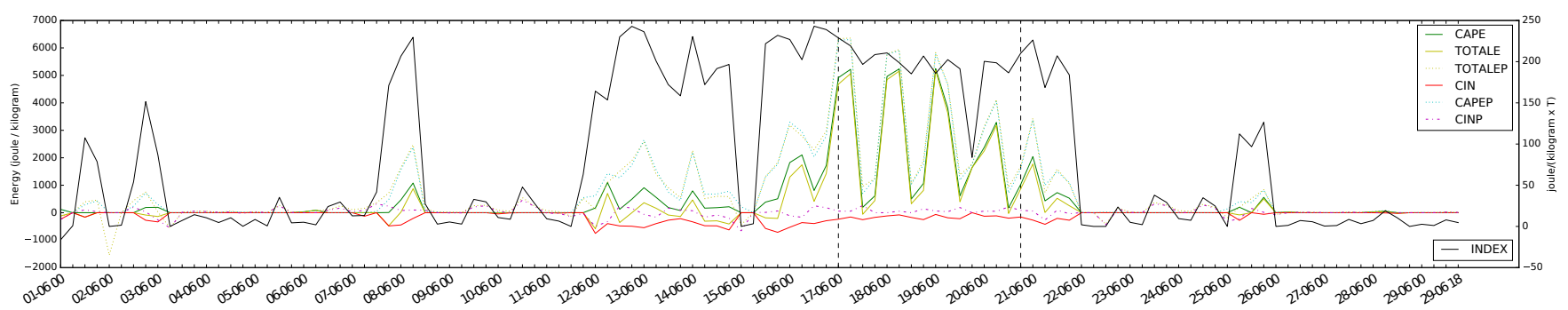

Figure 7. EFBI and its components for the wildfire in Pedrógão on June 2017 for the fire centroid $(-8.2252,39.952)$.

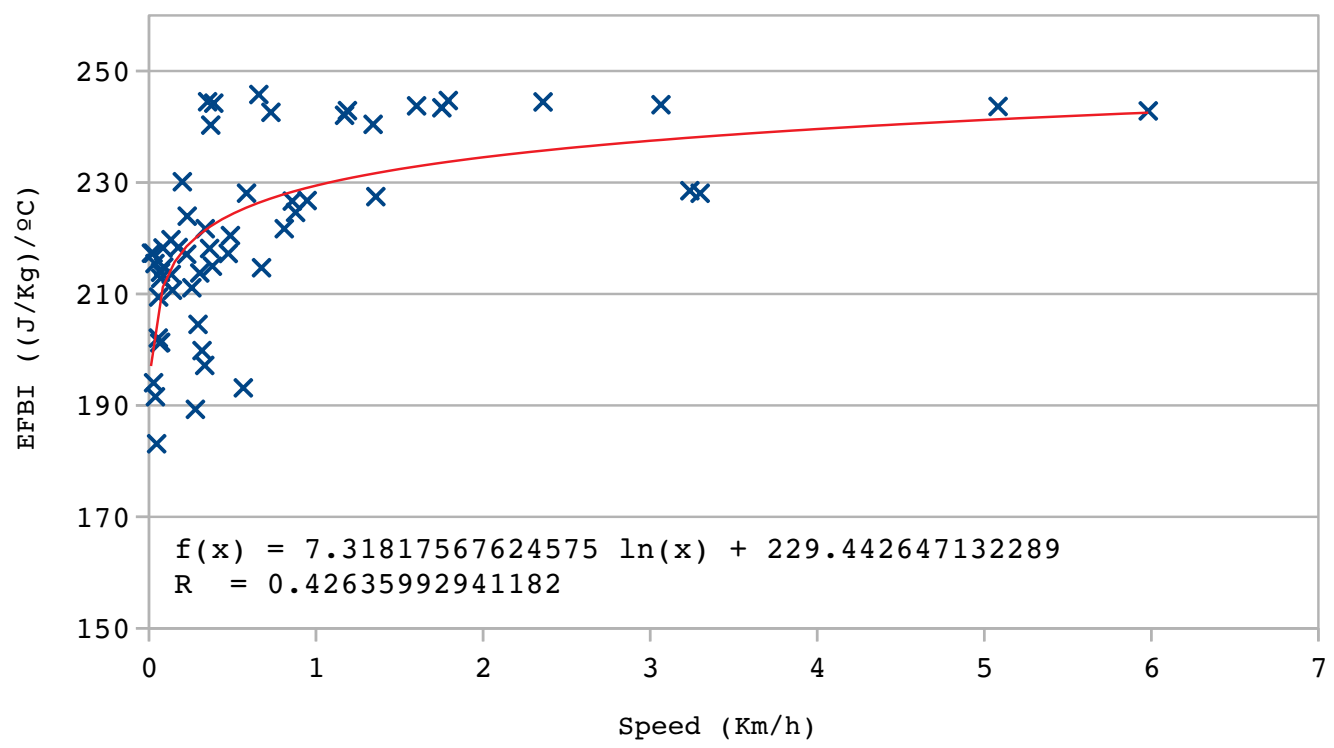

Figure 8. Scatter plot showing the maximum fire front speed and the values of the EFBI for each time step with a logarithmic trend line.

value and the estimated maximum fire speed. While a wide variety of values of EFBI are shown for low fire spread speed values, considerably higher EFBI values are shown for high speed values, compared with the rest of the point cloud. However, there is a weak correlation between the speed and the EFBI. It is worth mentioning that the blow up of the wildfire took place at the beginning; assuming that the fire was in convection almost from the first time steps, EFBI and fire spread speed may not show a strong correlation when looking at all the hourly time steps. However, Fig.8 shows that, even with an ongoing convective fire, the atmosphere stability context computed from a numeric model is still important.

\subsubsection{Forecast use Roboré, Bolivia 2019}

The values of the EFBI were computed using ERA5 forecast for the fire that took place in Roboré, Bolivia in 2019. This wildfire lasted 2 months and had a very variable fire behaviour. Figure 9 shows the daily burnt area for this wildfire using the 
240 GlobFire database. However, the level of detail of the fire mapping for this study case is not as accurate as in the previous case shown in Fig. 6.

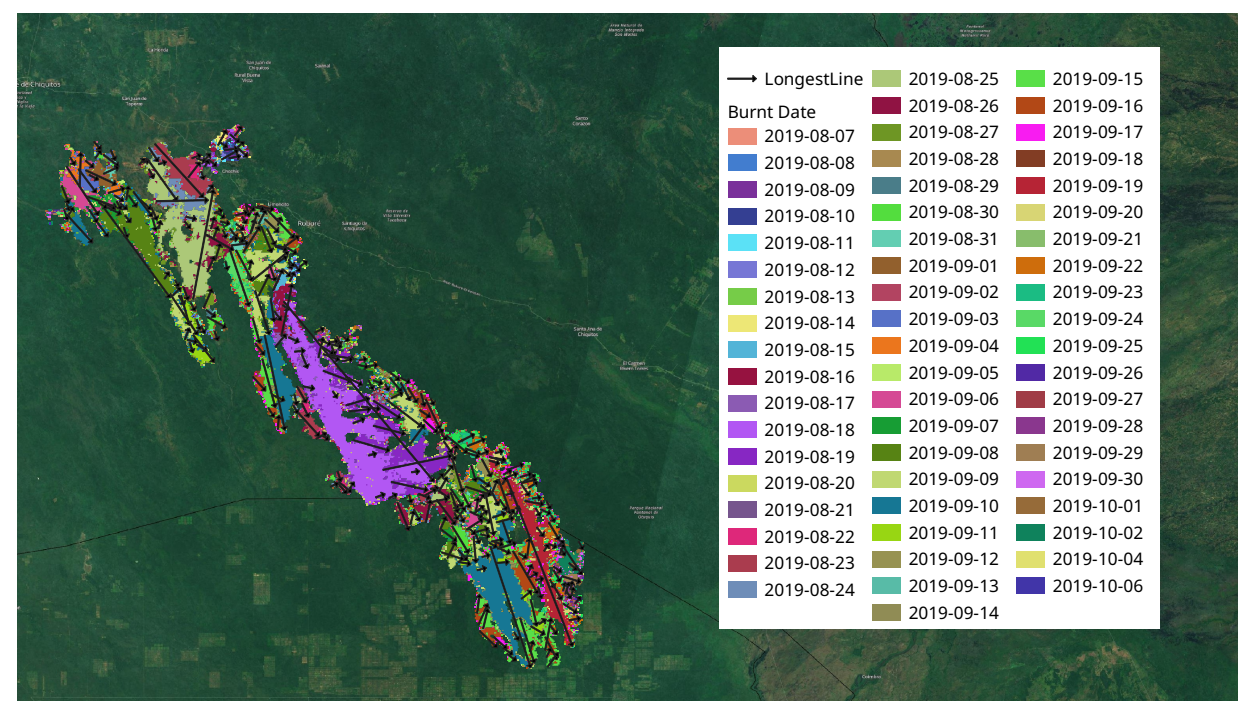

Figure 9. Daily burnt area for the duration of wildfire in Roboré, Bolivia in 2019. The maximum speed line between time steps is shown with a black arrow. The missing days do not have any daily burnt area in GlobFire. Background image @MapTiler (https://maptiler.com/copyright).

For this case, the EFBI was computed with three different deterministic forecasts of ERA5 on August 15 and 29 , and on September 3. During this wildfire, the EFBI forecast different periods of extreme behaviour caused by conditioned convection without a clear correlation as in the case shown in Section 3.1.1. For long duration wildfires that interact with the atmosphere it can be assumed that once a wildfire interacts strongly with the atmosphere, the trends of the EFBI are no longer valid, since they are based on a forecast that does not include the interaction. However, in the above case of Bolivia, our results points out that despite the fire-atmosphere interactions, the atmospheric stability trend may remain important and the values of the EFBI can be relevant for a second convection interaction. It is not feasible to find a correlation between the fire spread and the EFBI values in this case because the quality of the fire mapping is daily with a potential uncertainty of days. Also, the weather forecast that has been computed previously to a potential wildfire-atmosphere interaction may not depict the atmosphere around the fire just after a wildfire-atmosphere interaction.

Figure 10 shows the computation of the daily EFBI average joining the data from the different forecasts. In addition, the GlobFire database was retrieved and used to estimate the maximum daily fire run. Since the daily burnt area could have been mapped with some days of delay, an average has been applied to the maximum daily fire run using a time window of the 2 previous days. Figure 10 shows a peak of the EFBI followed by another one which started on 16th of August and a third peak on 22nd of August. After the first peak, the maximum fire longitude of the daily burnt areas had increased from the 16th to the 20th of August, while the highest runs of the fire happened between the 18th and 20th; the fire activity has another peak after August 22 having two observed pyroCb on 18th and 25th of August. After 25th August, the EFBI trends seem to be totally 
uncorrelated with the fire runs until 1st September. Afterwards, there is another peak on 7th of September which also seems to affect the fire runs and with 2 observed pyroCb on 7th and 8th of September. Later, EFBI and the maximum line length are again uncorrelated until 17th September when the relation there is the last peak with another pyroCb observed.

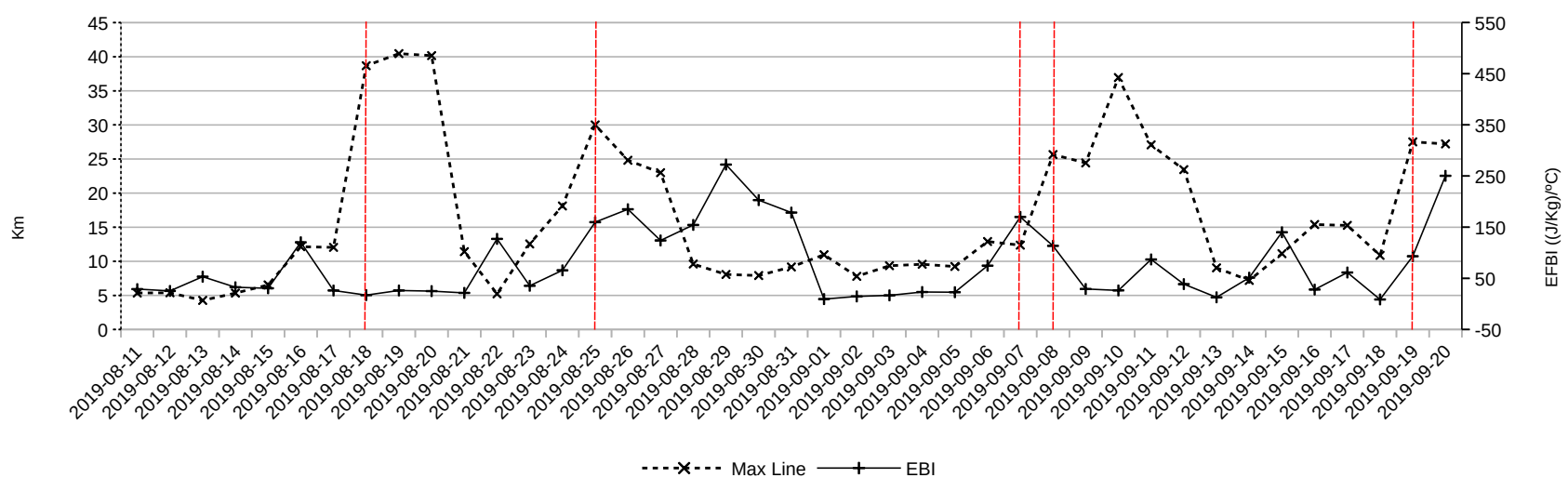

Figure 10. Maximum longitude of the the daily burnt area and the EFBI and its components for the wildfire in Roboré, Bolivia 2019. Vertical dashed red lines show when a pyroCb took place.

An example of pyroCb seen with Sentinel 2 displayed in Fig. 11, where parts of the plume are shown in white.
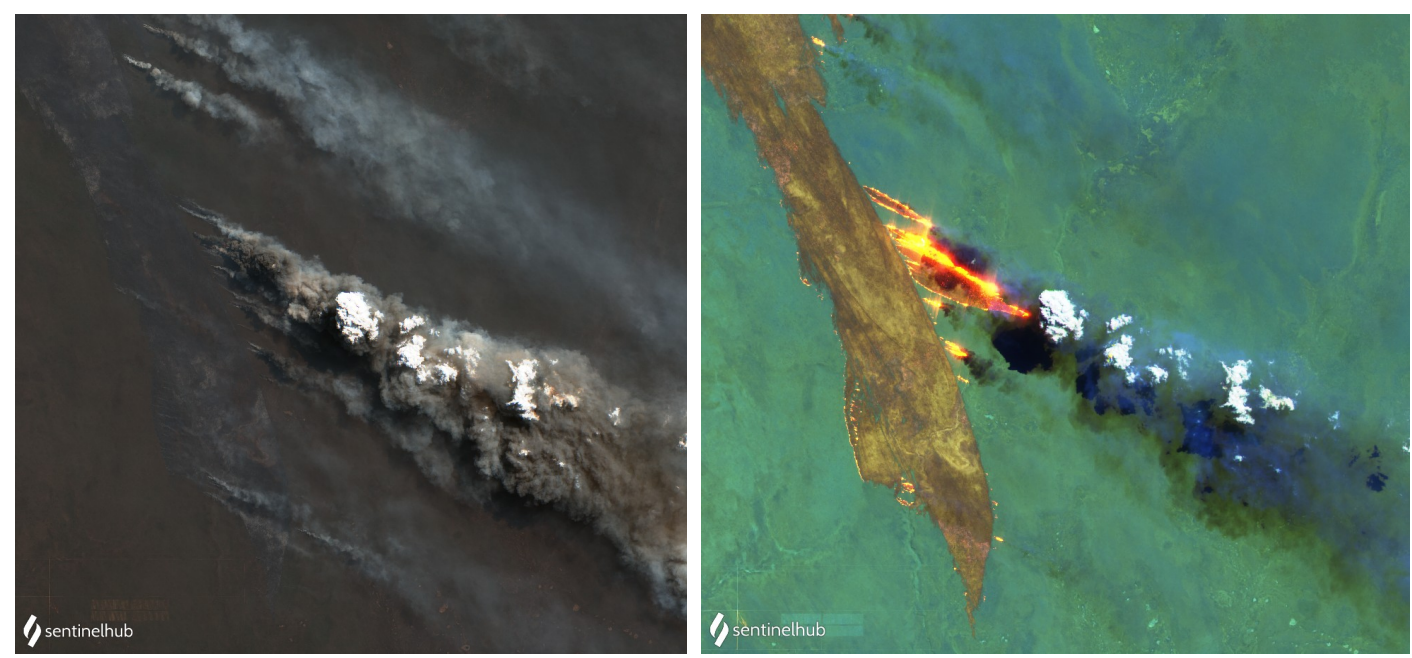

Figure 11. Sentinel 2, natural colour and atmospheric penetration, from right to left from S2 on 18th August. Roboré, Bolivia. 


\subsubsection{Wildfires Australia 2019}

The EFBI was computed with ERA5 reanalysis for this area at the time of the fires showing very high values. Figure 12 shows the maximum values of the EFBI overlapped with the active fires (thermal anomalies shown as black points) that took place the next day.
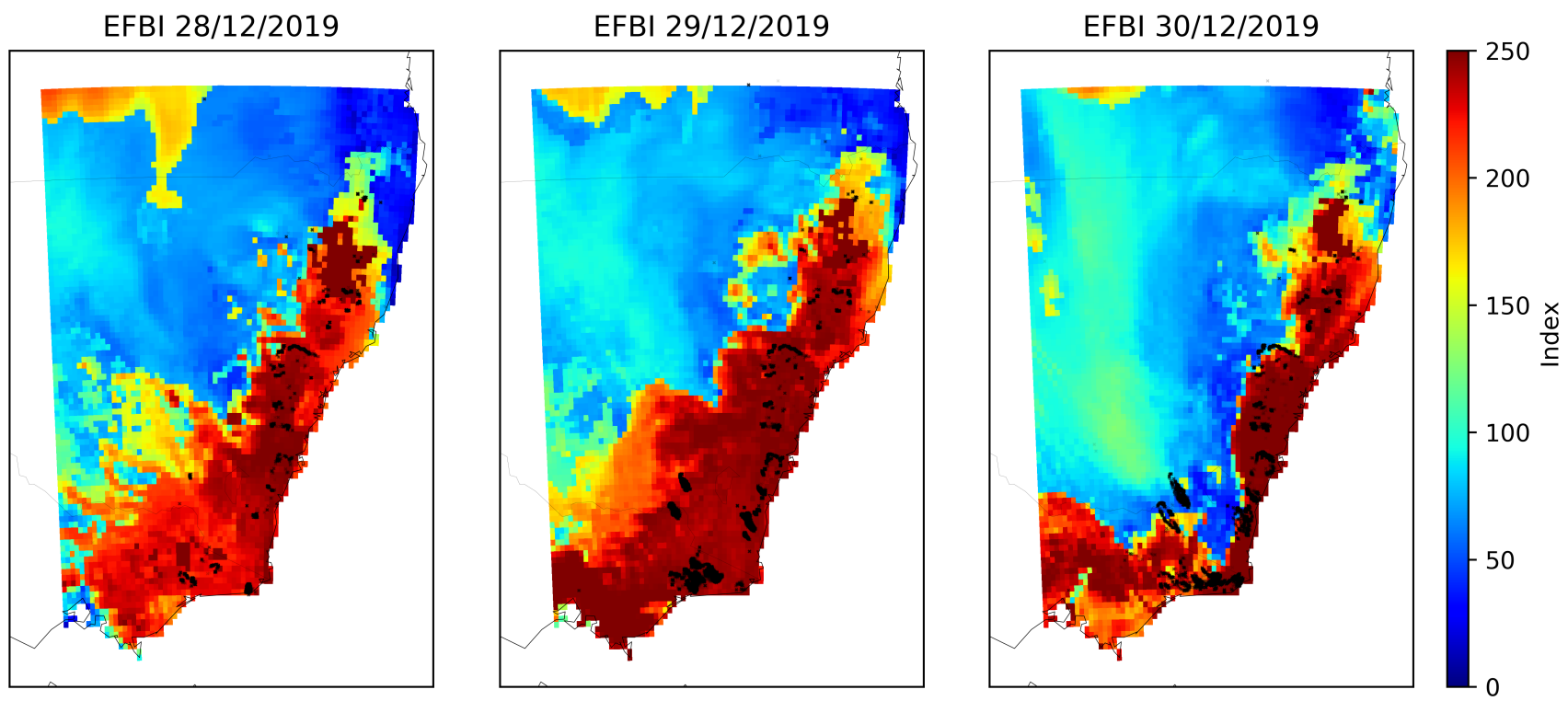

Figure 12. EFBI from 28/12/2019 to 30/12/2019 overlapped with the active fires (black dots) that took place the next day over southeast Australia.

It is worth mentioning that the assimilation system used to generate the ERA5 reanalysis dataset could partially affect the behaviour of the EFBI. In reanalysis, some of the consequences of heat release from the fire could be taken into account, while in the forecast for a given day those conditions would not be considered.

\section{Conclusions}

This work demonstrates that simple metrics of the atmospheric stability could provide valuable information for enhanced fire danger rating, increasing preparedness and improving safety and efficiency of firefighting operations. The EFBI could be used to detect days in which fires could exhibit convective extreme behaviour. On those days, fires could add an unpredictable interaction with atmospheric vertical profile, increasing fire behaviour due to plume dominated dynamics. However, EBI is subject to several factors which could cause uncertainty due to the wildfire-atmosphere interaction during a forecast and the resolution of data used. Also, convective fires are not the only kind of fire that can become extremely fast spreading. Despite this last fact, the approach used to differ between fast and slow fires at global scale demonstrates a potential use of the EFBI combined with 
the FWI. Moreover, the data used for the vertical profiles could be improved by estimating the surface temperature and relative humidity at the surface using the altitude of the fire event.

The EFBI holds the potential to improve fire danger forecast ratings at global scale. The initial testing presented in this article reached a $72 \%$ accuracy, discriminating the final size of fires between small $(<=500 \mathrm{ha})$ or large $(>=10000)$ at global scale. Accuracy could be improved by increasing the number of classes and using other input factors to discriminate wind driven fires in small bushes or grass which can become large fires but have low probability of becoming convective wildfires or breaking the atmosphere stability. These big fires are not discarded in this work. For instance, dry and strong catabatic wind-driven fires like those of the Mistral (Western Europe), Santa Ana and Diablo winds (California) or Zonda wind (Argentina and Chile) are not always fast wildfires caused by convection. These kinds of fires are not convective but are extreme anyway, and can reduce the accuracy reached in this work. This could relate also with the study case in Robore (Bolivia), that generated several pyroCb but it also had wind driven fire spreads.

The EFBI can be computed at least twice per day at global scale with up to 10 days forecast. For instance, using the Global Forecast System(GFS) for a 10 day forecast at 0.25 degrees of spatial resolution (approximately $25 \mathrm{~km}$ ), the computation of the EFBI at the global scale took 4 hours in a single node with linear speed up, using multiple cores.

The EFBI has shown high discriminatory power of large fires using ERA5 at 0.25 degrees resolution at hourly steps and GlobFire at 500m with a temporal resolution of 1 day. It showed a considerable relevance in the mutual information and in the discriminative power with the decision tree. It should be noted that the training of the neural network with only FWI values and its components, which are the fire danger indices most used worldwide, dropped the accuracy from $65.5 \%$ to $58 \%$. Our results also highlight the relevance of the GlobFire dataset to analyse fire behaviour and improve current danger ratings for extreme wildfires that may happen more frequently worldwide under climate change.

Using a high spatial and temporal resolution in the study case of Pedrógão Grande in Portugal, EFBI has shown a relation with the fire spread speed. Moreover, using the daily data of GlobFire for the fire behaviour in the case of Robore, EFBI could have been applied for the forecast of convective periods during the wildfire. For the last study case, this includes a cluster of extreme wildfires in Australia, high values of the EFBI match spatially with the occurrences of the such events. However, this work did not analyse the different behaviour of the fires inside the cluster.

Therefore, the EFBI has the potential to improve the current fire danger rating at global scale by establishing a fire typology, which could characterize potential explosive behaviour of wildfires under certain atmospheric conditions. 
https://doi.org/10.5194/nhess-2021-122

Preprint. Discussion started: 17 May 2021

(c) Author(s) 2021. CC BY 4.0 License.

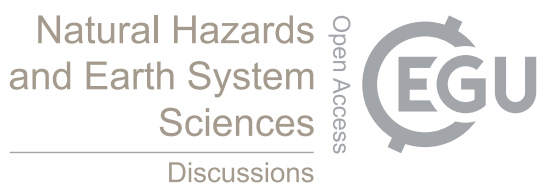

Acknowledgements. A non-published work between T.A and Thomas Petroliagkis in 2015 led to the proposed method after the development 310 of GlobFire, the customization of Metpy and the publication of ERA5. 


\section{References}

Artés, T., Oom, D., De Rigo, D., Durrant, T. H., Maianti, P., Libertà, G., and San-Miguel-Ayanz, J.: A global wildfire dataset for the analysis of fire regimes and fire behaviour, Scientific data, 6, 1-11, 2019.

Balch, J., Bradley, B., Abatzoglou, J., Nagy, R., Fusco, E., and Mahood, A.: Human-started wildfires expand the fire niche across the United States, Proceedings of the National Academy of Sciences of the United States of America, 114, 2-946, 2017.

Baptiste Filippi, J., Bosseur, F., Mari, C., Lac, C., Le Moigne, P., Cuenot, B., Veynante, D., Cariolle, D., and Balbi, J.-H.: Coupled atmospherewildland fire modelling, Journal of Advances in Modeling Earth Systems, 1, 2009.

Boschetti, L., Roy, D. P., Giglio, L., Huang, H., Zubkova, M., and Humber, M. L.: Global validation of the collection 6 MODIS burned area product, Remote Sensing of Environment, 235, 111490, 2019.

Byrd, R. H., Lu, P., Nocedal, J., and Zhu, C.: A limited memory algorithm for bound constrained optimization, SIAM Journal on scientific computing, 16, 1190-1208, 1995.

Deeming, J. E., Burgan, R. E., and Cohen, J. D.: The national fire-danger rating system-1978, vol. 39, Intermountain Forest and Range Experiment Station, Forest Service, US ..., 1977.

Defourny, P., Kirches, G., Brockmann, C., Boettcher, M., Peters, M., Bontemps, S., Lamarche, C., Schlerf, M., and Santoro, M.: Land cover CCI, Product User Guide Version, 2, 2012.

Delicado, N. T. S. and Gomes, A.: O GRANDE INCÊNDIO FLORESTAL DE PEDROGÃO GRANDE Análise Crítica.

Duane, A., Castellnou, M., and Brotons, L.: Towards a comprehensive look at global drivers of novel extreme wildfire events, Climatic Change, 165, 1-21, 2021.

Forthofer, J., Shannon, K., and Butler, B.: 4.4 simulating diurnally driven slope winds with windninja, USDA Forest Service, Rocky Mountain Research Station, Missoula, MT, 2009.

Friedlingstein, P., Jones, M., O’sullivan, M., Andrew, R., Hauck, J., Peters, G., Peters, W., Pongratz, J., Sitch, S., Le Quéré, C., et al.: Global carbon budget 2019, Earth System Science Data, 11, 1783-1838, 2019.

Giglio, L., Justice, C., Boschetti, L., and Roy, D.: MCD64A1 MODIS/Terra+ Aqua Burned Area Monthly L3 Global 500 m SIN Grid V006 [Data Set], NASA EOSDIS Land Processes DAAC: Sioux Falls, SD, USA, 2015.

Haines, D. A. and Service, U. F.: A lower atmospheric severity index for wildland fires, 1988.

Hersbach, H.: The ERA5 Atmospheric Reanalysis., in: AGU fall meeting abstracts, 2016.

"Independente", C. T.: Relatório: Análise e apuramento dos factos relativos aos incendios que ocorreram em Pedrógão Grande, Castanheira de Pera, Ansiao, Alvaiázere, Figueiró dos Vinhos, Arganil, Góis, Penela, Pampilhosa da Serra, Oleiros e Sertã, entre, $17,2017$.

Keetch, J. J. and Byram, G. M.: A drought index for forest fire control, vol. 38, US Department of Agriculture, Forest Service, Southeastern Forest Experiment, 1968.

Khaykin, S., Legras, B., Bucci, S., Sellitto, P., Isaksen, L., Tence, F., Bekki, S., Bourassa, A., Rieger, L., Zawada, D., et al.: The 2019/20 Australian wildfires generated a persistent smoke-charged vortex rising up to $35 \mathrm{~km}$ altitude, Communications Earth \& Environment, 1 , $1-12,2020$.

Kraskov, A., Stögbauer, H., and Grassberger, P.: Estimating mutual information, Physical review E, 69, $066138,2004$.

Lareau, N., Nauslar, N., and Abatzoglou, J. T.: The Carr Fire vortex: a case of pyrotornadogenesis?, Geophysical research letters, 45, 13-107, 2018a. 
Lareau, N. P., Nauslar, N. J., and Abatzoglou, J. T.: The Carr Fire Vortex: A Case of Pyrotornadogenesis?, Geophysical Research Letters, 45, 13,107-13,115, https://doi.org/https://doi.org/10.1029/2018GL080667, 2018b.

Lombardo, K. A. and Colle, B. A.: Convective storm structures and ambient conditions associated with severe weather over the northeast

United States, Weather and forecasting, 26, 940-956, 2011.

Mandel, J., Beezley, J. D., and Kochanski, A. K.: Coupled atmosphere-wildland fire modeling with WRF-fire, arXiv preprint arXiv:1102.1343, 2011.

McArthur, A. G.: Fire behaviour in eucalypt forests, 1967.

Mell, W., Jenkins, M. A., Gould, J., and Cheney, P.: A physics-based approach to modelling grassland fires, International Journal of Wildland Fire, 16, 1-22, 2007.

Moncrieff, M. W. and Miller, M. J.: The dynamics and simulation of tropical cumulonimbus and squall lines, Quarterly Journal of the Royal Meteorological Society, 102, 373-394, 1976.

Pausas, J. G. and Keeley, J. E.: A burning story: the role of fire in the history of life, BioScience, 59, 593-601, 2009.

Pausas, J. G. and Keeley, J. E.: Epicormic resprouting in fire-prone ecosystems, Trends in Plant Science, 22, 1008-1015, 2017.

Pedregosa, F., Varoquaux, G., Gramfort, A., Michel, V., Thirion, B., Grisel, O., Blondel, M., Prettenhofer, P., Weiss, R., Dubourg, V., Vanderplas, J., Passos, A., Cournapeau, D., Brucher, M., Perrot, M., and Duchesnay, E.: Scikit-learn: Machine Learning in Python, Journal of Machine Learning Research, 12, 2825-2830, 2011.

Pinto, M. M., DaCamara, C. C., Hurduc, A., Trigo, R. M., and Trigo, I. F.: Enhancing the fire weather index with atmospheric instability information, Environmental Research Letters, 15, 0940b7, https://doi.org/10.1088/1748-9326/ab9e22, 2020.

Pirsko, A. R., Sergius, L. M., and Hickerson, C. W.: Causes and behavior of a tornadic fire-whirlwind, Res. Note PSW-RN-061. Berkeley, CA: US Department of Agriculture, Forest Service, Pacific Southwest Forest and Range Experiment Station. 13 p, $61,1965$.

Potter, B.: The Haines Index-it's time to revise it or replace it, International journal of wildland fire, 27, 437-440, 2018a.

Potter, B. E.: Quantitative Evaluation of the Haines Index's Ability to Predict Fire Growth Events, Atmosphere, 9, 177, 2018b.

Ross, B. C.: Mutual information between discrete and continuous data sets, PloS one, 9, 2014.

Rothermel, R. C.: A mathematical model for predicting fire spread in wildland fuels, vol. 115, Intermountain Forest and Range Experiment Station, Forest Service, United ..., 1972.

San-Miguel-Ayanz, J., Schulte, E., Schmuck, G., Camia, A., Strobl, P., Liberta, G., Giovando, C., Boca, R., Sedano, F., Kempeneers, P., et al.: Comprehensive monitoring of wildfires in Europe: the European forest fire information system (EFFIS), in: Approaches to managing disaster-Assessing hazards, emergencies and disaster impacts, IntechOpen, 2012.

San-Miguel-Ayanz, J., Oom, D., Artes, T., Viegas, D., Fernandes, P., Faivre, N., Freire, S., Moore, P., Rego, F., and Castellnou, M.: Forest fires in Portugal in 2017, in: Science for Disaster Risk Management 2020: acting today, protecting tomorrow, edited by Casajus Valles, A., Marin Ferrer, M., Poljansek, K., and Clark, I., Publications Office of the European Union, Luxembourg, https://doi.org/doi:10.2760/438998, 2019.

Shi, Y., Matsunaga, T., Saito, M., Yamaguchi, Y., and Chen, X.: Comparison of global inventories of CO2 emissions from biomass burning during 2002-2011 derived from multiple satellite products, Environmental pollution, 206, 479-487, 2015.

Short, K. C.: Spatial wildfire occurrence data for the United States, 1992-2015, Forest Service Research Data Archive, https://doi.org/https://doi.org/10.2737/RDS-2013-0009.4, 2017.

Van Wagner, C., Forest, P., et al.: Development and structure of the canadian forest fireweather index system, in: Can. For. Serv., Forestry Tech. Rep, Citeseer, 1987. 
https://doi.org/10.5194/nhess-2021-122

Preprint. Discussion started: 17 May 2021

(C) Author(s) 2021. CC BY 4.0 License.

(c) (i)

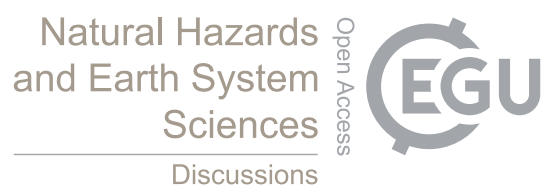

385 Van Wagner, C. et al.: Structure of the Canadian forest fire weather index, vol. 1333, Environment Canada, Forestry Service, 1974.

Vitolo, C., Di Giuseppe, F., Barnard, C., Coughlan, R., San-Miguel-Ayanz, J., Libertà, G., and Krzeminski, B.: ERA5-based global meteorological wildfire danger maps, Scientific data, 7, 1-11, 2020. 